\title{
Una biografía de Carrera sin adjetivos: algunas notas a los comentarios de Daniel Palma y Sergio Serulnikov
}

\section{A biography of Carrera without adjectives: some notes to comments by Daniel Palma and Sergio Serulnikov}

BEATRIZ BRAGONI

\section{Resumen}

El texto ofrece un conjunto de reflexiones sobre las estrategias narrativas de interpretación y verificación de la biografía de José Miguel Carrera a la luz de las claves de lectura propuestas por los historiadores, Daniel Palma y Sergio Serulnikov.

Palabras clave: José Miguel Carrera revolución - independencia - identidades políticas - biografía

\begin{abstract}
The text provides a set of reflections on the narrative strategies of interpretation and verification of the biography of José Miguel Carrera in the light of the key reading proposed by historians, Daniel Palma and Sergio Serulnikov.
\end{abstract}

Keywords: José Miguel Carrera - revolution - independence - political identities biography

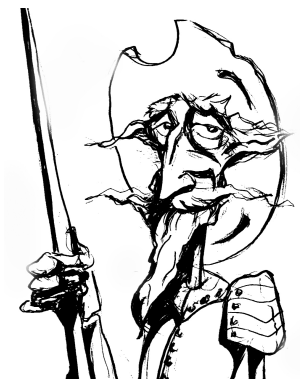

Recibido con pedido de publicación el 5 de octubre de 2016 Aceptado para su publicación el 30 de octubre de 2016 Versión definitiva recibida el 15 de noviembre de 2016

Beatriz Bragoni, Instituto de Ciencias Humanas, Sociales y Ambientales (INCIHUSA), Consejo Nacional de Investigaciones Científicas y Técnicas - Universidad Nacional de Cuyo, Argentina; e-mail: bbragoni@mendoza-conicet.gob.ar 
1. Ante todo celebro la iniciativa de poner en diálogo esta biografía de José Miguel Carrera con las ofrecidas por mis colegas, y también agradezco los generosos y estimulantes comentarios de Daniel Palma y Sergio Serulnikov. Ambos resultan incitantes en relación a las claves de lectura que cada uno hizo primar por lo que emprenderé un camino necesariamente selectivo de reflexiones que tiene como propósito exponer las razones que me condujeron a proponer el trayecto carrerino como vector narrativo y explicativo de las formas de acción política en el curso de las guerras de independencia.

Naturalmente, el trayecto político de José Miguel resulta ejemplar en el plano de la nutrida documentación que atestigua su desempeño público como en el hermenéutico; se trata de un personaje nacido en el seno de linajes patricios tardocoloniales, convertido en líder popular de la revolución chilena hasta la derrota de 1814, devenido en rival de quienes conducían los resortes de la maquinaria política y judicial en las Provincias Unidas del Río de la Plata, y en Chile, y que fuera fusilado en Mendoza por atentar contra la libertad de América. Semejante silueta revolucionaria modelada en una amplísima geografía política, exhibe la dramática metamorfosis de una vida individual que, por supuesto, y como sugiere Serulnikov, no amerita ser interpretada como representativa de un grupo social pero que por tal, es capaz de ofrecer huellas indicativas para capturar, como lo señala Palma, el papel del antagonismo y la lucha política de las elites o dirigencias revolucionarias en el complejo proceso de formación de las nuevas identidades políticas que acompasó el desmoronamiento del orden colonial, y la convulsa aventura republicana. Tal como evoca Daniel Palma en clave testimonial, solo recientemente la figura de José Miguel ameritó ser expuesta en Santiago, la base territorial de su poder, en un plano de igualdad heroica con su tenaz adversario, Bernardo O'Higgins, y ese deslizamiento no resulta ajeno al progresivo declive de las historiografías nacionalistas que desde el siglo XIX, contribuyeron a forjar el panteón nacional.

2. Una y otra vez he leído con gran interés los comentarios de mis colegas y he detectado algunas notas comunes. Una de ellas no deja aún de fascinarme en tanto atañe a las variaciones y determinaciones del proceso de identificación americana y chilena que exhibe la trayectoria de José Miguel en un lapso de tiempo relativamente breve, aunque para nada sorprendente, si seguimos a Kosselleck, el de la revolución. Sergio lo hace de manera mucho más explícita, tal vez, por las resonancias que en la historiografía hispanoamericana adquirieron las influyentes hipótesis de F. X. Guerra sobre la dimensión atlántica de la nación española, esgrimida por los liberales gaditanos en el "bienio crítico", y las no menos gravitantes interpretaciones ofrecidas por J. C. Chiaramonte en torno a la ausencia de identidades nacionales. ${ }^{1}$ Sin duda, la

${ }^{1}$ GUERRA, Francois Xavier Modernidad e Independencias. Ensayos sobre las revoluciones hispánicas. MAPFRE, Madrid, 1992; CHIARAMONTE, José C. "Formas de identidad política en el Río de la Plata después de la independencia", en Boletín del Instituto de Historia Argentina y Americana, Dr. 
cadena de evidencias que atestiguan la precipitación de la adscripción americana carrerina en detrimento de la hispánica o peninsular, guardan estrecha conexión con los agravios u ofensas del que fue objeto en vísperas de la crisis dinástica, y en el curso de la guerra que practicó en defensa del Rey contra los franceses, y de las impresiones obtenidas en la travesía marítima que lo condujo de Cádiz a Valparaíso las cuales, según su testimonio, transformó el clásico motivo del resentimiento criollo en acciones políticas dispuestas a radicalizar su opción patriótica. Sergio da en la tecla al observar que el giro introducido por José Miguel a la revolución chilena brinda elementos de prueba suficientes sobre el fin de la ambigüedad en materia de autogobierno, y para asociar, y no distinguir, revolución e independencia. No se trata en su caso solo de las iniciativas institucionales y liturgias públicas que puso en marcha (que hicieron coincidir la celebración patriótica con alegorías y el calendario festivo de la independencia norteamericana), ni tampoco como bien ha sugerido Julio Pinto Vallejos, de su pretensión para nada frustrada de ensanchar las bases sociales de su liderazgo a través de la militarización y politización del "bajo pueblo".2 Se trata, especialmente, del enfático rechazo del líder patriota al controvertido tratado de Lircay, promovido por $\mathrm{O}^{\prime}$ Higgins junto al oficial arribado por orden de Abascal, el que ratifica su opción por la independencia que se verá reforzada a raíz de las rivalidades territoriales y políticas que terminaron por minar los cimientos del emprendimiento patriótico y anticolonial.

3. El proceso de "extrañamiento" que siguió a la derrota militar, ese fenómeno que hizo decir al salteño José de Moldes, "Dispersos, emigrados, errantes, aún no sabemos la Patria que hemos de vivir", estuvo lejos de esmerilar el componente identitario de origen (o local) del iracundo patriota chileno. Por el contrario, la clasificación de emigrado dispuesta por el gobernador de Cuyo, José de San Martín, a los chilenos expulsados de su Patria (que incluyó tropas, familias

Emilio Ravignani, núm. 1, Buenos Aires, 1989, pp. 71-92; “Acerca del origen del estado en el Río de la Plata", en Anuario IEHS, núm. 10, Tandil, 1995, pp. 27-50; Ciudades, provincias, Estados: Orígenes de la Nación Argentina, 1800-1846, Ariel, Buenos Aires, 1997; Nación y Estado en Iberoamérica. El lenguaje político en tiempos de las independencias, Sudamericana, Buenos Aires, 2004. También resultan de interés los tempranos abordajes sobre las identidades nacionales realizados por Pilar González Bernaldo de Quirós, “La 'identidad nacional' en el Río de la Plata post-colonial. Continuidades y rupturas con el Antiguo Régimen”, en Anuario IEHS, núm. 12, Tandil, 1997, pp. 109-122. Además, Jorge Myers, “Identidades porteñas. El discurso ilustrado en torno la nación y el rol de la prensa: El Argos de Buenos Aires, 1821-1825", en ALONSO, Paula (comp.) Construcciones impresas. Panfletos, diarios y revistas en la formación de los estados nacionales en América Latina, 1820-1920, Fondo de Cultura Económica, Buenos Aires, 2003, pp. 39-63.

2 PINTO VALLEJOS, Julio y VALDIVIA ORTÍZ DE ZÁRATE, Verónica ¿Chilenos todos? La construcción social de la nación (1810-1840), LOM, Santiago de Chile, 2009. PINTO VALLEJOS, Julio "El rostro plebeyo de la Independencia chilena 1810-1830", en Nuevo Mundo, Mundos Nuevos, Debates, 2010, [En línea], Puesto en línea el 18 mayo 2010. URL: http://nuevomundo.revues.org/59660 
completas, y población libre y esclava), sería la que trazaría una línea demarcatoria del accionar público de los incluidos en esa categoría en las Provincias del Plata. Que el apelativo de emigrado haya adquirido en aquella coyuntura un significado político no constituye ninguna novedad si se tiene en cuenta que se trataba de un vocablo (y experiencia) de reciente uso, y que remitía como en tantas otras cosas, a las invenciones semánticas procedentes de la revolución francesa. ${ }^{3}$ Pero es la propia apelación y su asociación con el veto oficial a intervenir en la vida pública en "este territorio" (como lo destacó Posadas), lo que conduce a considerar, por un lado, el arbitrio de un recurso destinado a reducir (o excluir) la intervención política de los recién llegados, y por el otro, a la dificultad de amalgamar el pretendido componente de unidad americana con las adscripciones territoriales de estirpe borbónica, que resultaron resignificados por los desiguales, aunque conectados, trayectos revolucionarios.

En torno a este último punto, el juicio criminal de 1818 condensa, y al mismo tiempo, despliega la relativa unidad del proceso político, las disputas políticas en la médula del poder revolucionario, y lo que no es menos relevante, los planos superpuestos de interpretación del delito de sedición contra los Estados erigidos en ambas jurisdicciones, y la radicación territorial del proceso judicial. Daniel está en lo cierto al señalar la centralidad que su tratamiento obtuvo en la economía del libro en tanto se convierte en prisma analítico de privilegio para deconstruir la apropiación de lenguajes jurídicos y procedimientos judiciales por parte del personal político revolucionario para liquidar (o exterminar, tal el lenguaje de época) a los disidentes o adversarios. Tal restitución, y como lo anticipé en un artículo previo, ${ }^{4}$ obedecía a la completa ausencia de estudios académicos en Argentina y en Chile, ${ }^{5}$ y a la inspiradora cantera procedente de las historiografías euroatlánticas, y de la aportada por los microhistoriadores italianos quienes habían hecho de los expedientes judiciales vectores interpretativos esclarecedores de las formas de intervención social, y de las no menos indicativas maneras de interrogar los nexos entre "hecho" y "prueba". Pero si el juicio criminal de 1818 permitía poner a prueba hipótesis relativas a la gravitación de usos y conceptos de la justicia de antiguo régimen en la nueva coyuntura, su mayor atracción reposaba en la incidencia del contexto político como generador de prueba, y de su articulación con la generación de argumentos cuya legitimidad reposaba en la autoridad de los

\footnotetext{
3 BOFFA, Massimo "Emigrés", en FURET, F. y OZOUF M. Dictionnaire Critique de la Révolution francaise. Acteurs, Flammarion, París, 2007, pp. 315-329.

${ }^{4}$ BRAGONI, Beatriz "Justice révolutionnaire au Amerique du Sud pendant les guerres des indépendances hispano-americaine. Le procès des frères Carrera (1818)", en Annales. Histoire, Sciences Sociales, núm. 5, París, 2008, pp. 949-976.

${ }^{5}$ Todavía recuerdo la paciente labor de separar las páginas del volumen de la Revista de la Biblioteca Nacional (1947) que reproducía el expediente alojado en el AGN, con un cuchillo que me facilitó el gentil Abel en la biblioteca del Instituto Emilio Ravignani.
} 
Estados independientes cuya fragilidad, y eventuales fracasos, difícilmente podían eludir una adecuada caracterización histórica sin que ella guardara alguna filiación con la estirpe romántica. ${ }^{6}$

Asimismo, y tal vez aquí radique una respuesta oblicua al interrogante formulado por Daniel sobre el componente social del liderazgo de los Carrera y sus concepciones sobre el cambio social, la trama de testimonios directos e indirectos, exhumados del expediente, resultaban sugestivos al momento de evaluar el tejido de solidaridades políticas (y étnicas) de los reclusos, como también las inconsistencias y restricciones de los sistemas normativos (recupero aquí a Levi), como herramienta intersticial de la acción social. Allí, y en un plano au ras de sol, es posible apreciar la urdimbre social que sostuvo aún en los márgenes, y en la reclusión, la expectabilidad pública de los hermanos Carrera, como también permite entender la incidencia del proceso judicial en la cohesión de los cuadros militares del Ejército Unido en Chile que gravitó en la alarma que siguió a la derrota de Cancha Rayada, la cual obligó a San Martín a inflamar el espíritu patriótico en Santiago para reunir fuerzas dispersas, y frenar el pesimismo y el miedo que envolvía a los partidarios de la independencia en vísperas al triunfo de Maipú.

Con esta respuesta no pretendo eludir el interrogante de Daniel sino dar el puntapié inicial de un asunto que juzgo crucial para entender la naturaleza del liderazgo político en cuestión imantado en la fragua de las revoluciones y de las independencias en estos rincones australes del antiguo imperio español. Dicha problemática también me permite agrupar la tercera nota subrayada por Sergio sobre la simultaneidad o concurrencia de ambos fenómenos en las concepciones y prácticas políticas ensayadas por José Miguel, las cuales tomarían distancia de hipótesis recientes que aconsejan desacoplar la invención revolucionaria de la independencia que le siguió. ${ }^{7}$ Ambas inquietudes, como sabemos, han estado en el centro de la agenda historiográfica lo cual me exime de consideraciones puntuales; no obstante ello, creo oportuno recoger algunas notas indicativas que apuntan a relacionar el "factor individual" con el proceso político general que trastocó los cimientos del orden colonial en Chile, y dio origen a uno nuevo. La primera es de índole historiográfica e interpela el "juicio histórico" que sobrevive aún sobre el protagonismo carrerino a la luz del derrotero de la Patria Vieja (1810-1814), y la cohesión relativa de las elites que ni el remplazo institucional, ni tampoco la guerra logró desarticular haciendo de

\footnotetext{
${ }^{6}$ BOTANA, Natalio Monarquía y república. La encrucijada de la independencia, Edhasa, Buenos Aires, 2016.

7 TERNAVASIO, Marcela "La revolución y sus silencios", en PALACIOS, Marco (coord.) Las independencias hispanoamericanas. Interpretaciones 200 años después, Grupo Editorial Norma, Bogotá, 2009, pp. 157- 182; ENTIN, Gabriel "Enigmas y dilemas de la independencia", en ENTIN, G. et al Crear la Independencia. Historia de un problema argentino, Capital Intelectual, Buenos Aires, 2016, pp. 9-23.
} 
ella el zócalo seminal del estado republicano edificado sobre la base del esquema de poder portaliano. Al respecto, la historiografía no duda atribuir a José Miguel un rol destacado en la radicalización del emprendimiento patriótico que catapultó el carácter anodino y ambiguo del curso político abierto con la formación de la junta en 1810: dicha interpretación reposa primordialmente en la puesta en marcha de iniciativas reformistas de variada índole e impacto social, como también en el impulso militarizador, en la producción de ingenierías simbólicas, y de un reglamento constitucional que aceptó al Rey sobre la base del autogobierno chileno, y el rechazo a la égida peruana, entre otros asuntos; los historiadores también subrayan las marcas de origen "aristocrático" de su liderazgo, y entienden su adscripción ideológica e institucional afín al republicanismo como medio apropiado para dotar de legitimidad el ejercicio de poder construido. A propósito del sesgo "manipulador" del desempeño carrerino, la conclusión de Jocelyn Host-Letelier es contundente: "Carrera no fue un revolucionario pero hizo uso de un lenguaje republicano", como tampoco "aseguró la independencia", aunque "no estuvo en el bando que se inclinaba por entablar negociaciones con Abascal". 8

4. Tales advertencias (o precisiones) resultan atractivos en varios sentidos aunque, tal vez, el más revelador resida en la multifacética y necesaria combinación de descripciones que exigen la caracterización de la cosmovisión y acción política carrerinas lo cual nos devuelve a un punto de partida básico de interpretación sobre las revoluciones e independencias hispanoamericanas: este es, el que entiende el cambio o ruptura política e institucional (destitución de autoridades, autogobierno e independencia de la monarquía española), en relación a las condiciones endógenas y externas que lo hicieron posible, y el que recomienda tener en cuenta sus implicancias sociales. ${ }^{9}$ En torno a ello, resulta difícil atribuir al factor individual, en este caso Carrera, formas de acción política diferentes a las documentadas, las cuales, vale recordar, guardan completa sintonía con su mayor o menor proximidad con los resortes de poder institucionales y sociales. De la variación de esa posición relativa en el esquema de poder en Chile, y de su absoluta marginación en el Río de la Plata, emanan reveladoras evidencias de la manera en que las reglas del juego político exigieron a las dirigencias revolucionarias arbitrar estrategias de movilización popular (más allá de cualquier sincero convencimiento), instrumentar incentivos materiales y simbólicos para sostenerlas, y establecer alianzas estables ( $u$ ocasionales) con actores políticos hasta entonces inesperados. Por

\footnotetext{
8 JOCELYN HOST-LETELIER, Alfredo La independencia en Chile. Tradición, modernización y mito, Random House Mondadori, Santiago de Chile, 2009, pp. 210-211.

9 FRADKIN, Raúl "Los actores de la revolución y el orden social", en Boletín de Historia Argentina y Americana, Dr. Emilio Ravignani, $2^{\circ}$ Semestre, núm. 33, Buenos Aires, 2010, pp. 79-90, $\mathrm{y}$ "Las formas de hacer la guerra en el litoral rioplatense y el retorno de un viejo problema: guerras de independencia y guerras civiles", en BANDIERI, Susana (comp.) La historia económica y los procesos de independencia en América Hispana, Prometeo, Buenos Aires, 2010, pp. 167-214.
} 
consiguiente, y aunque resulten demasiado austeras las evidencias relativas a la manera en que José Miguel asoció el cambio político con el cambio social, el proceso de radicalización exhibido en el Río de la Plata que siguió a la empresa conspirativa, habría de precipitar y llevar al extremo ese principio también polifónico, aunque estructurante del lenguaje de las independencias, este es, el de la soberanía de los pueblos. De su adecuación o adscripción (manipulable $u$ oportunista, según se prefiera) en el escenario rioplatense encapsulado entre 1818 y 1820, también se extraen impresiones valiosas en torno al fortalecimiento de sus convicciones republicanas en oposición al monarquismo imaginado por los directoriales, y muy especialmente al rechazo de la intervención del ejército y gobierno de Buenos Aires en la política y gobierno chilenos; y es justamente, la virulenta denuncia sobre el carácter invasor del ejército antes libertador, la que destaca la eficacia relativa del argumento en la sedimentación de sentimientos de pertenencia nacionales. De la eficacia de esa interpelación inscripta en sus proclamas, manifiestos y avisos a los chilenos, como de las sagaces caricaturas que fueron conocidas incluso en Lima, y los resultados prácticos de su inclusión en la liga de jefes federales que asestó un golpe de muerte al sistema de unión y al congreso edificado por sus adversarios, se extraen evidencias reveladoras: la fugaz aceptación del sargento devenido en coronel de sumar la fuerza militar del batallón de cazadores, acantonado en San Juan, a la empresa de destituir a O'Higgins que incluía 1000 chilenos, la concesión del gobernador Sarratea al momento de suministrarle 700 soldados chilenos para reinventar el Ejército Restaurador, y la no menos indicativa reacción de los cuerpos cívicos porteños manifiestamente hostiles a la formación de un ejército de chilenos en el corazón de la ciudad. Finalmente, la cadencia de la asociación de extranjero y chileno estructuró la errática, aunque furibunda, política de exterminio en el desafortunado trayecto en las provincias ya des-unidas. En consecuencia, el "factor Carrera" entre 1818 y 1821 en el Río de la Plata opera como elemento disruptivo del orden/desorden político instituido, y de igual modo, con capacidad de coaligar alianzas políticas interprovinciales.

5. Por último, la historia de Carrera nos devuelve entonces al clásico problema del "balance entre un hombre y una época". Una historia singular que retrata la revolución americana y su drama sin que ella anticipe el curso de la política y lo político posterior, ni tampoco que atribuya a los actores de carne y hueso algún tipo de racionalidad capaz de anticipar todos y cada uno de los resultados de sus aciertos o fracasos. Una restitución del trayecto social y político que opta por esquivar adjetivaciones, y propone entenderlo en función de los contextos inestables (personales, familiares, institucionales y políticos), y en constante redefinición. Un actor político en relación a sus circunstancias que haga comprensible su peso, y que sea capaz de ilustrar el margen de maniobra de la iniciativa o libertad individual. La historia de Carrera en Chile y en el Río de la 
Plata, pone en escena en definitiva, lo contingente, es decir, las formas en que el actor enfrenta las posibilidades y límites de los contextos en que se inscriben sus relaciones, sus prácticas y sus pasiones. Una biografía contextual, Le Petit X sugerida por Sabina Loriga como vía resolutiva a los dilemas a los que suelen enfrentarse los historiadores para romper el exceso de coherencia del discurso histórico, y reflexionar no solo sobre lo que ha sido, sino también para capturar las incertidumbres del pasado.

Mendoza, septiembre de 2016 